\section{EMBnet - The Global Bioinformatics Network, in 2013: A Silver Anniversary}

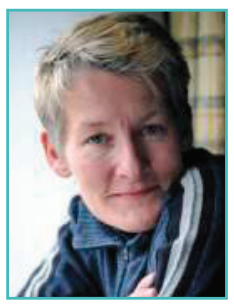

\section{Teresa K Attwood}

University of Manchester, Manchester, United Kingdom

Received 18 March 2013; Published 19 August 2013

\section{Summary}

EMBnet's 2013 Annual General Meeting (AGM) and associated events were hosted in the TRYP Valencia Oceanic Hotel, Valencia, Spain, from 14 to 18 May. The AGM, the silver anniversary of EMBnet's foundation, provided a timely opportunity both to review our progress since the "EMBnet Moving Forward: 2010 \& beyond" workshop hosted in Ruvo di Puglia, Italy (Attwood ef al., 2010), and to showcase the work of our allied SeqAhead project. EMBnet has undergone significant changes since 2010: it has rebranded and launched a new website; it has formed new alliances; it has incubated new initiatives (notably, GOBLET': (Global Organisation for Bioinformatics Learning, Education \& Training) and multidisciplinary research projects (namely, SegAhead ${ }^{2}$ and AllBio $^{3}$ ); and it has formally introduced structural changes to streamline our activities and broaden our membership.

The events allied to the AGM included a fullday EMBnet hands-on tutorial ${ }^{4}$ on "RNA-seq and ChIP-sea data analysis", given by Endre Barta (U. of Debrecen, Hungary) and Eija Korpelainen (CSC- IT Center for Science, Finland), and on "NGS and structural Biology", given by Goran Neshich (EMBRAPA, Brazil), Jose R. Valverde (CNBCSIC, Spain) and Gert Vriend (CMBI, Holland); the two-day SeqAhead "The Next NGS Challenge:

\footnotetext{
1 http://www.mygoblet.org/

2 http://www.seqahead.eu/

3 http://www.allbioinformatics.eu/doku.php

$4 \quad$ http://www.thenextngschallenge.org/index.php/program/ngs-workshop
}

Data Processing and Integration ${ }^{5 "}$ conference and Management Committee meeting; a fullday EMBnet workshop; and finally, the business meeting itself. Here, we review the motivation for the EMBnet workshop, and present its main conclusions.

\section{Background}

EMBnet's 2013 AGM was a significant event, marking the 25th anniversary since its foundation (in 1988), making it the oldest, widest bioinformatics network in the world. However, notwithstanding EMBnet's history and substantial contributions to the field of bioinformatics during the past three decades (e.g., see Attwood et al., 2011), in 2010, the Executive Board ${ }^{6}$ set out a vision for a new EMBnet, one that would allow it to evolve more effectively as a global organisation. Amongst its key recommendations, the Executive Board suggested that there was an urgent need to:

1. review, streamline and clarify EMBnet's current membership scheme;

2. review how EMBnet might form strategic alliances with other bioinformatics networks and organisations;

3. consider how it might compete more strategically in global funding calls;

4. review the evolving role and internal structure of EMBnet.journal, and consider more tactical publishing strategies; and, in light of these considerations,

5. review and revamp EMBnet's current name, brand and website.

Ultimately, we wished to strengthen EMBnet's foundations, to create a competent, valuable and focused organisation, both to complement existing and emerging bioinformatics institutes, networks, associations and societies worldwide, and to maintain EMBnet's relevance in 2010 and beyond (Attwood et al., 2010). Our goal was to better define EMBnet's role in European and global contexts, and open new avenues via which the organisation could move forward, for the benefit of its global membership.

The 2013 AGM, EMBnet's silver anniversary, was thus an opportune moment to reflect on how far we'd progressed towards meeting the 2010 recommendations.

\footnotetext{
5 http://www.thenextngschallenge.org/

6 http://www.embnet.org/about/executive-board
} 


\section{Update on Achievements}

Improving the EMBnet brand \& promoting our activities more effectively

A taskforce had been set up to consider how to improve EMBnet's brand and Web presence. Working closely with the Publicity and Public Relations Project Committee (P\&PR PC), a new logo was introduced, together with the strapline, "Bioinformatics without borders", attempting to encapsulate EMBnet's global mission more effectively. The challenging task of designing a new website was also commenced. After exploring several design prototypes, we engaged Itico (a non-profit Private Limited Company supporting the iAnn project) to implement the ideas - see Figure 1. Although the website is still undergoing revisions, it's gratifying to know that it has already attracted some positive feedback from the community via Twitter.

In parallel with these developments, we had also proceeded to evolve the highly successful EMBnet.news ${ }^{8}$ into a peer-reviewed journal EMBnet.journal $^{9}$ (Figure 2, left-hand pane). The additional time taken to produce peer-reviewed issues, however, left a gap in our ability to make timely news announcements. We therefore ex-

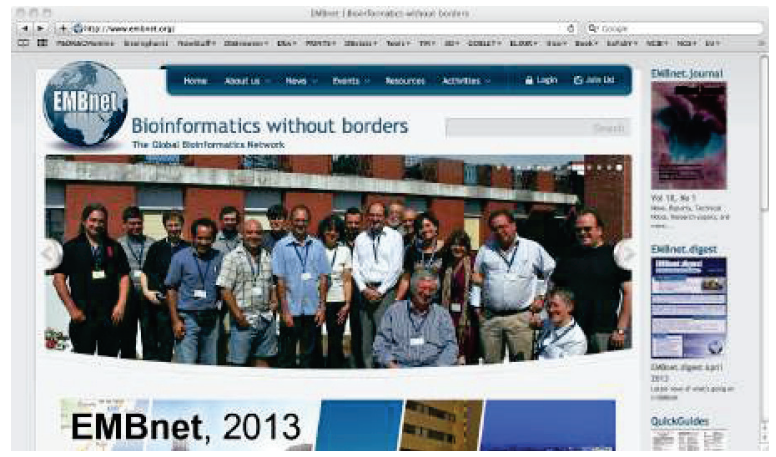

Figure 1. Screen capture showing the new EMBnet website, logo and strapline.

perimented with a new Web-based publication, so-called EMBnet.digest (Figure 2, middle pane), to try to give a flavour of EMBnet's activities and upcoming events on a more regular (monthly) basis. As this appeared to be a popular mechanism for disseminating news, the P\&PR PC subsequently overtook its production, and also created a new 'look \& feel' (Figure 2, right-hand pane).

During the last 18 months in particular, the Executive Board also worked closely with the P\&PR PC to establish sponsorship/patronage agreements to promote the work of EMBnet more widely, mostly notably at ISCB Latin America $2012^{10}$
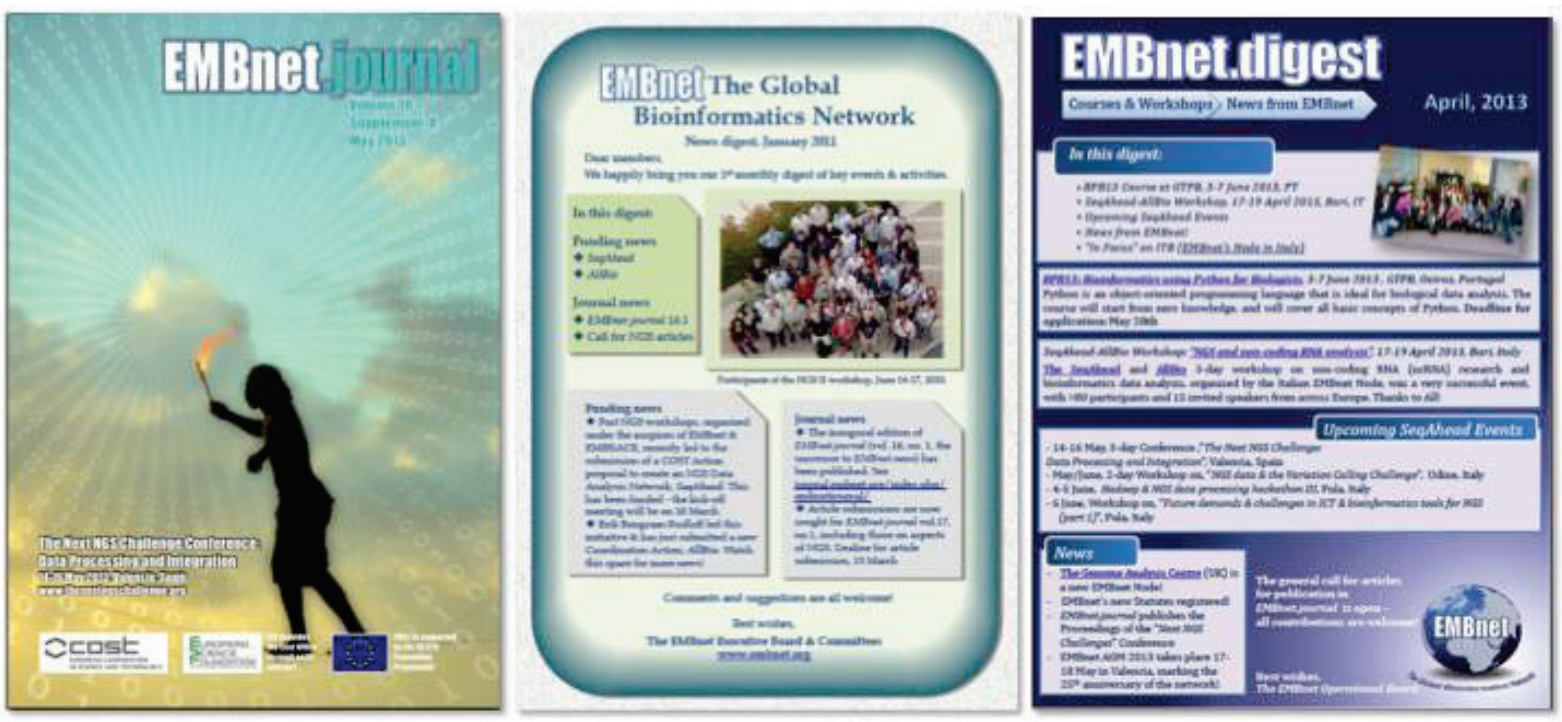

Figure 2. From left to right, screen-captures showing the previous cover of EMBnet.journal, the original 'look \& feel' of EMBnet. digest, and the current re-designed digest.

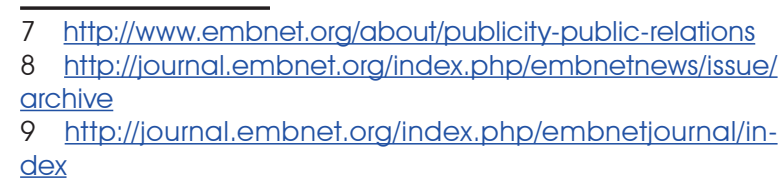

10 http://www.iscb.org/iscb-latinamerica2012 


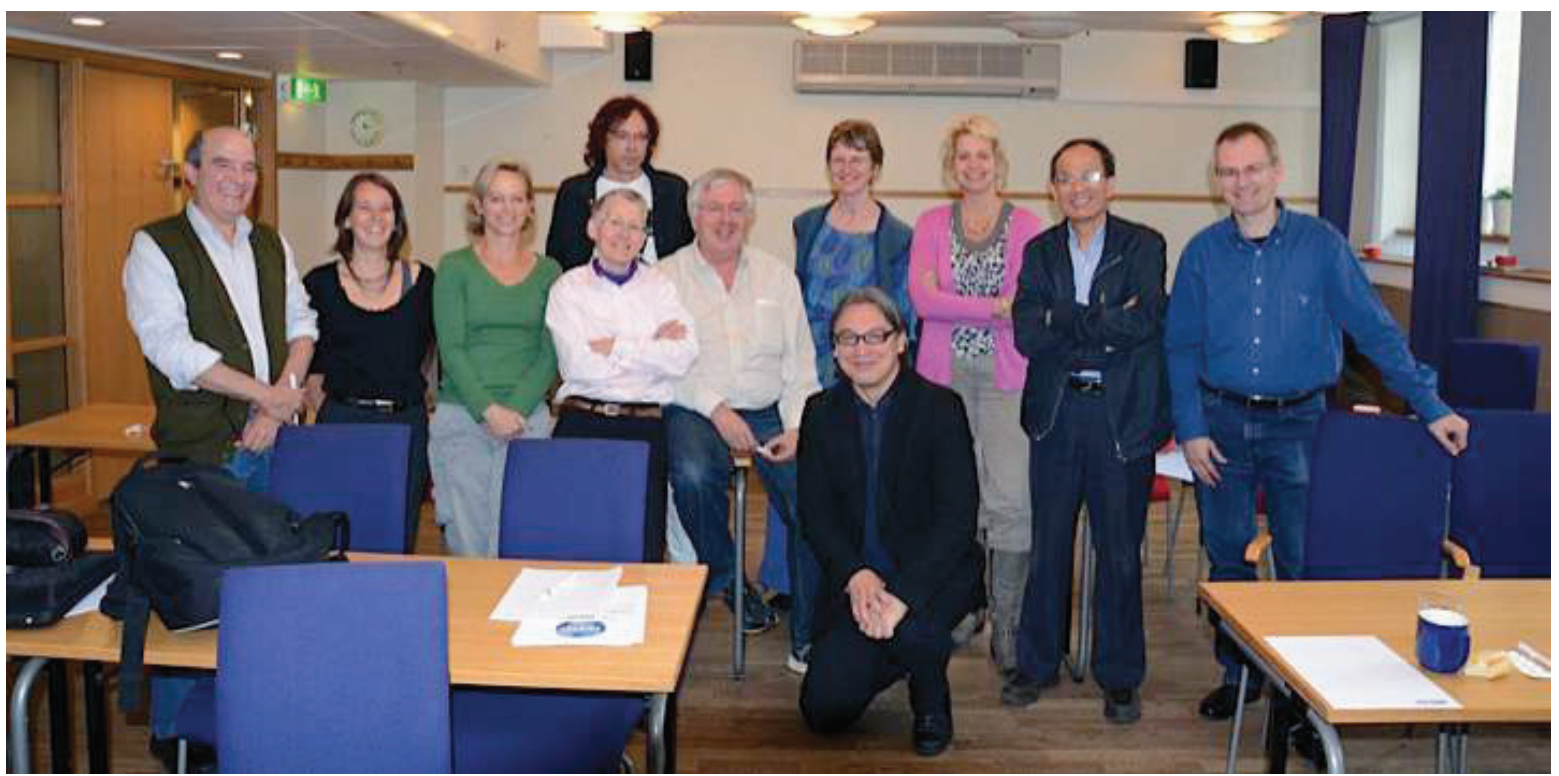

Figure 3. The $\mathrm{B}^{3} \mathrm{CB}$ kick-off meeting that launched GOBLET.

(Chile), BITS 201211 (Italy), NETTAB $2012^{12}$ (Italy) and ISCB Africa ASBCB $2013^{13}$.

\section{Securing strategic alliances with other organi- sations}

Two very significant alliances have been formed since 2010, both related to EMBnet's commitment to bioinformatics training. First, having become a formal affiliate of ISCB, a press release was made announcing the intention of the ISCB and EMBnet to collaborate on bioinformatics education and training (ISCB press release $\left.{ }^{14}, 2011\right)$. This will ensure that, whenever possible, EMBnet training courses are incorporated into ISCB meetings, especially those in developing regions. Importantly, the collaboration also establishes a framework for fostering future EMBnet and ISCB Student Council aCtivities for the benefit of the global bioinformatics community.

The second alliance was extremely ambitious. A small workshop was held during the 2012 AGM in Uppsala, Sweden, at which representatives from nine other Bioinformatics, Biotechnology, Biocuration and Computational Biology (B3CB) societies, networks and projects came together to discuss the need for a more holistic view of bioinformatics training across the globe - see

\footnotetext{
11 http://bits2012.dmi.unict.it/conferencevenue.html

12 http://www.nettab.org/2012/

13 http://www.iscb.org/iscbafrica2013

14 http://journal.embnet.org/index.php/embnetjournal/article/view/217/459
}

Figure 3. The participants concluded that, building on the achievements of the Bioinformatics Training Network (Schneider et al., 2012), a Global Organisation for Bioinformatics Learning, Education and Training (GOBLET) was needed to coordinate world-wide bioinformatics training activities: to share, not duplicate, effort; to share, not duplicate, cost; to work together in a mutually respectful way towards common solutions and a sustainable future. To this end, a Memorandum of Understanding (MoU) was drawn up to establish GOBLET as a legally registered foundation, following the successful model of EMBnet. Since the ten founding members (EMBnet, ISCB, ASBCB, ISB, SolBio, APBioNet, BTN, SeqAhead, NBIC and EBI) signed the MoU, 16 further organisations have pledged their commitment to formally create and support the GOBLET Foundation ${ }^{15}$.

\section{Competing for funds for some of our activities}

Since 2010, two important research projects have also been incubated and funded, both relating to EMBnet's involvement in NGS activities. First was the Next Generation Sequencing Data Analysis Network (SeqAhead) COST Action (BM1006), the kick-off meeting for which took place in Brussels, Belgium in March 2011. By establishing a strong European network of NGS, data-analysis and informatics centres, SeqAhead aims to facilitate and stimulate the exchange of data, protocols,

$\overline{15 \text { www.mygoblet.org }}$ 

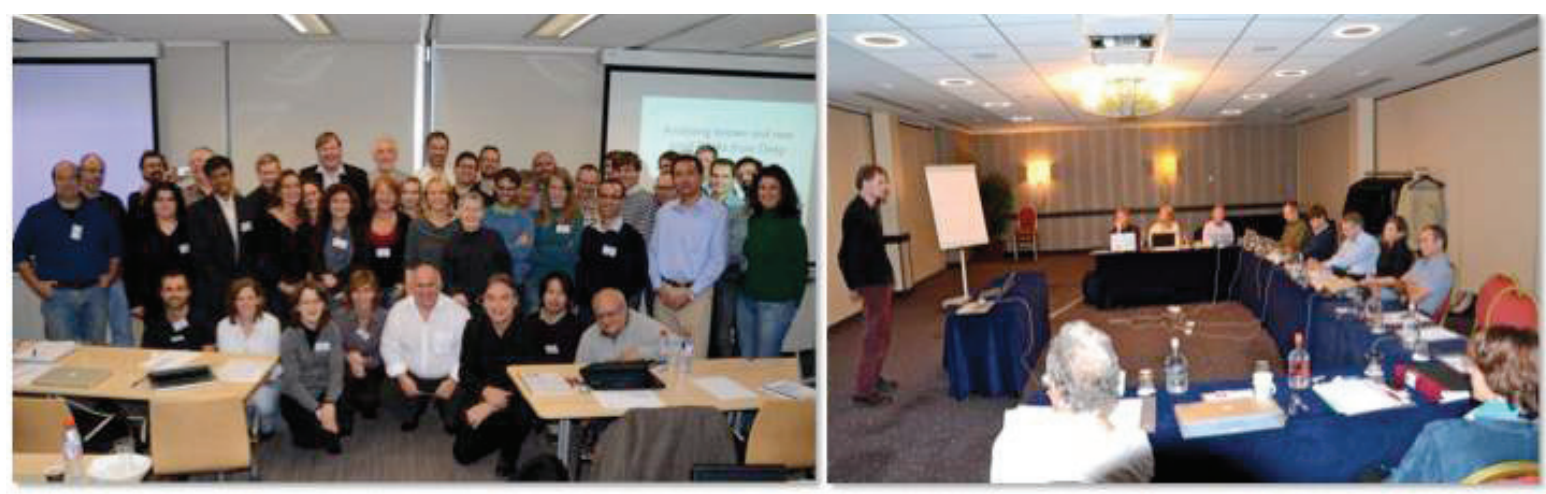

Figure 4. From left to right, SeqAhead's first scientific meeting and AllBio's kick-off meeting.

software, experiences, ideas and, crucially, training. Erik Bongcam-Rudloff is the grant-holder and project Chair, and Terri Attwood the project Vice Chair; Andreas Gisel leads Work Group (WG) 2, which is developing an action plan for NGS bioinformatics; Eija Korpelainen leads WG 3, which concerns the design and implementation of software for NGS data analysis; and Gert Vriend leads WG 5, which coordinates the project's dissemination, education and training activities (www.segahead.eu) - see Figure 4 (left-hand pane).

The second success came in the form of the EU Coordination Action, AllBio, which aims to broaden the bioinformatics infrastructure to unicellular, animal and plant science. The kick-off meeting was also held in Brussels, in November 2011 - Figure 4 (right-hand pane). Once again, Erik Bongcam-Rudloff coordinates the project, and partners include Andreas Gisel, Terri Attwood, Eija Korpelainen, Gert Vriend and Laurent Falquet (www.allbioinformatics.eu).

\section{Structural changes}

Arguably, the most significant development since 2010 was the consent, during the 2012 AGM, to radical revisions of EMBnet's statutes and byelaws, in order both to streamline how we conduct aspects of our business (especially our election processes) and, for the first time, to allow admission of individual members.

To this end, we removed the requirement for government mandates, and implemented an online payment system, allowing new members (both individual and organisational) to join more efficiently. Accordingly, EMBnet will no longer have National Nodes, although we will continue to recognise those Nodes that have National status; and there will no longer be a requirement for
Node re-elections, as member status will relate strictly to the payment of the annual subscription fee. In addition, the new statutes oblige the Executive Board (EB) to work more closely with Project Committee (PC) Chairs, via a formal Operational Board (OB), and allow the PC Chairs greater flexibility to recruit enthusiastic members to help with their activities. Overall, these changes should allow future AGMs to run more efficiently: e.g., elections will only be held for members of the EB and PC Chairs (committee members will not require election); and there will be less obligatory reporting, and hence more time for discussion and action!

The new statutes were finally ratified in April 2013. Since then, we've welcomed one new organisational member - The Genome Analysis Centre (TGAC), Norwich, UK, represented by Vicky Schneider - and several new individual members.

\section{The 2013 AGM workshop}

Taking advantage of the new statutes, and the greater time afforded for discussion, the 2013 AGM was preceded by a workshop (see Figure 5). This was organised into four main sessions, focusing on issues relating to i) membership fees and sponsorship; ii) the website, EMBnet.digest, social networking and QuickGuides; iii) EMBnet.journal and fund-raising; and iv) video-conferencing and future priorities. The first two of these sessions were run as parallel break-out groups, followed by plenary reportage; the remaining two were run as general group discussions. There were also several 'sticky-note' exercises, to encourage participants to think 'on the hoof' about a range of important topics, including potential future Editorial Board members for EMBnet.journali additional 


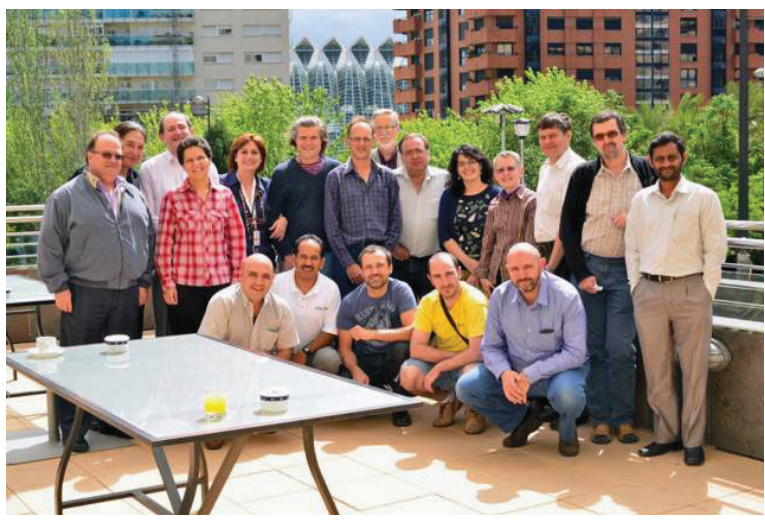

Figure 5. Participants of the 2013 AGM workshop.

pages, sections and/or functionalities that could be included in the new website; potential sources of funding; and EMBnet's future missions and priorities. The main outcomes of the discussions and exercises are reviewed below.

\section{Membership fees}

In previous meetings, the $\mathrm{OB}$ had discussed the possibility of changing EMBnet's fee structure: for organisations, the proposal was to drop the fee from $€ 1,000$ per annum to $€ 500$; for individuals, the proposal was to introduce a fee of $€ 50$.

We wished to use this opportunity to explore with the full EMBnet Board whether the proposals were optimal, what might be their pros and cons, and whether there were alternative models that we could adopt. We also wished to consider whether we could offer any new membership benefits, and, where new proposals had been made, what might be their associated benefits.

The discussions on this topic were surprisingly congruent: all groups agreed that a hybrid model of fees would be optimal, in which some organisations would be able to pay an annual fee of $€ 1,000$ and others $€ 500$, while individuals would pay $€ 50$, or $€ 15$ if they were students (but the student rate would apply, say, for only three years for any individual, without supporting documentation).

The principal benefit for organisations paying $€ 1,000$ would be that their travel to the AGM would be reimbursed (up to a ceiling of €500). In terms of additional benefits of EMBnet membership that could potentially be added to the website, several suggestions were made: these included opportunities to share facilities; to host visiting staff or students; to access a list of trainers; and the possibility to provide sponsorship for students (see next section). Another valuable suggestion was that we could explore the idea of joining student membership with the ISCB.

\section{Sponsorship}

In recent years, EMBnet has been approached by several organisations seeking sponsorship, patronage or endorsement of their events. While there is much to be gained by promoting EMBnet's activities in this way, nevertheless, a policy and an appropriate budget would need to be in place in order for us to be able to respond efficiently and consistently to requests of this type.

The questions for the group therefore concerned the types of event we should sponsor, the level of annual budget that could be set aside to support these or other strategic events (in terms of visibility, to prompt new alliances, collaborations, and so on), and what forms of sponsorship EMBnet might be able to provide.

There was general consensus that EMBnet should sponsor a range of events (not just those planned by networks/societies/organisations with whom EMBnet already has special agreements), but preferably those in which mutual benefits are apparent. The kinds of sponsorship offered by EMBnet could include keynote speakers at meetings, or trainers at courses, tutorials and so on; travel bursaries for students; and conference gadgets. It was proposed that we should set aside between 10 and $15 \%$ of EMBnet's annual surplus in order to be able to respond to future sponsorship requests.

Website, EMBnet.digest and Social Networking The new website had been up and running for a while, but the migration of content from the previous site had been an enormous task, and many aspects remained to be resolved. Perhaps more importantly, the burden of maintenance was falling to one or two individuals alone. Help was clearly needed to progress some aspects of the site: these included the addition of EMBnet news and events; updating contents with new activities, new projects, additional resources, etc.; adding and updating member details; maintaining the mailing lists, and so on.

During the workshop, a little time was spent reviewing the website, and demonstrating the ease with which all members can login to the system, upload news and events, and generally manage, and take responsibility for, their own content. Overall, participants seemed very happy with 
the new site. However, it was recommended to reconsider the rotating banner, which was causing problems in countries where bandwidth is a problem. Another key recommendation was to explore how to adopt a more unified image for promoting EMBnet via member websites. All such feedback will allow us to build on the site and generally improve the image that EMBnet projects to the world.

The 'look and feel', and management of EMBnet.digest were also discussed. Here again, most of the work falls to one or two individuals, and help is needed to collate information more efficiently. The principal outcome of the discussions was that we should consider adopting a more exciting 'look and feel', which could be prototyped in the coming months. Moreover, a schedule of 'In focus' contributions was agreed from now until October 2013, commencing with a focus on the AGM in the May issue.

There was also a general discussion around the presence of EMBnet on social networks (via media such as Linkedln, ResearchGate, Twitter, Facebook, Wikipedia, etc.). EMBnet already has a successful Linkedln site and a Wikipedia entry. Given that EMBnet doesn't have resource to dedicate to all such activities, it was suggested that the website could be made 'social media friendly', to allow news, events, features and so on to be exported to relevant social media, as and when appropriate, more easily.

\section{QuickGuides}

QuickGuides $^{16}$ have been a long-standing and useful output of EMBnet. However, maintaining or updating them, and writing new ones, requires commitment and effort. As many of the Guides had not been updated and no new Guides had been created for several years, the question was whether we should keep them.

In the discussion that followed, all agreed that we should maintain EMBnet's portfolio of QuickGuides, and that these should be peer-reviewed in order to maintain quality. Two complementary models for managing the Guides were proposed: i) that they should be made available via the GOBLET website, as part of its educational/ training content; and ii) that they should be managed via the Open Journal System (OJS). As these models are not mutually exclusive, it would seem sensible to proceed with both!

16 http://www.embnet.org/embnet-quickguides

\section{EMBnet.journal}

The transition from the highly successful EMBnet. news to the new, peer-reviewed EMBnet.journal has been a major challenge. While several supplements containing conference abstracts have been published, the main journal issues have been much more difficult to produce. Therefore, the discussions on EMBnet.journal focused primarily on how it could attract more research articles and/or other content, and whether the journal should accept advertisements, in order to bolster its income.

It's clear that the principal problem facing the journal is lack of dedicated manpower. All agreed that hiring a paid, part-time assistant would be helpful, and that a small part of EMBnet's surplus should be set aside annually to achieve this. Several other conclusions were reached: first, that all members of EMBnet should provide a 'good' article, or perhaps encourage a student in their group to submit some of their work; second, that the journal could include a new 'book review' section; third, that the journal should include a section dedicated to the Node 'InFocus' pages of EMBnet.digest, highlighting the special events, activities and/or initiatives of EMBnet's Nodes and members; and finally, that we should explore what models other journals adopt with regard to the inclusion of advertisements.

\section{Fund-raising}

Fund-raising is an important activity for augmenting EMBnet's finances and for galvanising its work - without dedicated funds, it is much harder always to rely on the good will and dedication of particular individuals. This discussion therefore centred on what types of activity EMBnet should seek to get funded, and what funding opportunities might be available to support them.

There was general agreement that the types of activity that EMBnet would like to be in a position to fund, or offers it would like to be in a position to make, would include travel fellowships for students; support for EMBnet speakers and/or trainers; administrative support for EMBnet;ournal; EMBnet events (tutorials, workshops, conferences, etc.); and joint research projects.

The first, most obvious, mechanism by which to enable such activities and benefits was to increase EMBnet's membership. We are, of course, hopeful that the new, streamlined process for joining EMBnet, with is easy-to-use online payment system, will help to widen our membership; 


\section{BEPORTS EMBnet.jourilal 19.1}

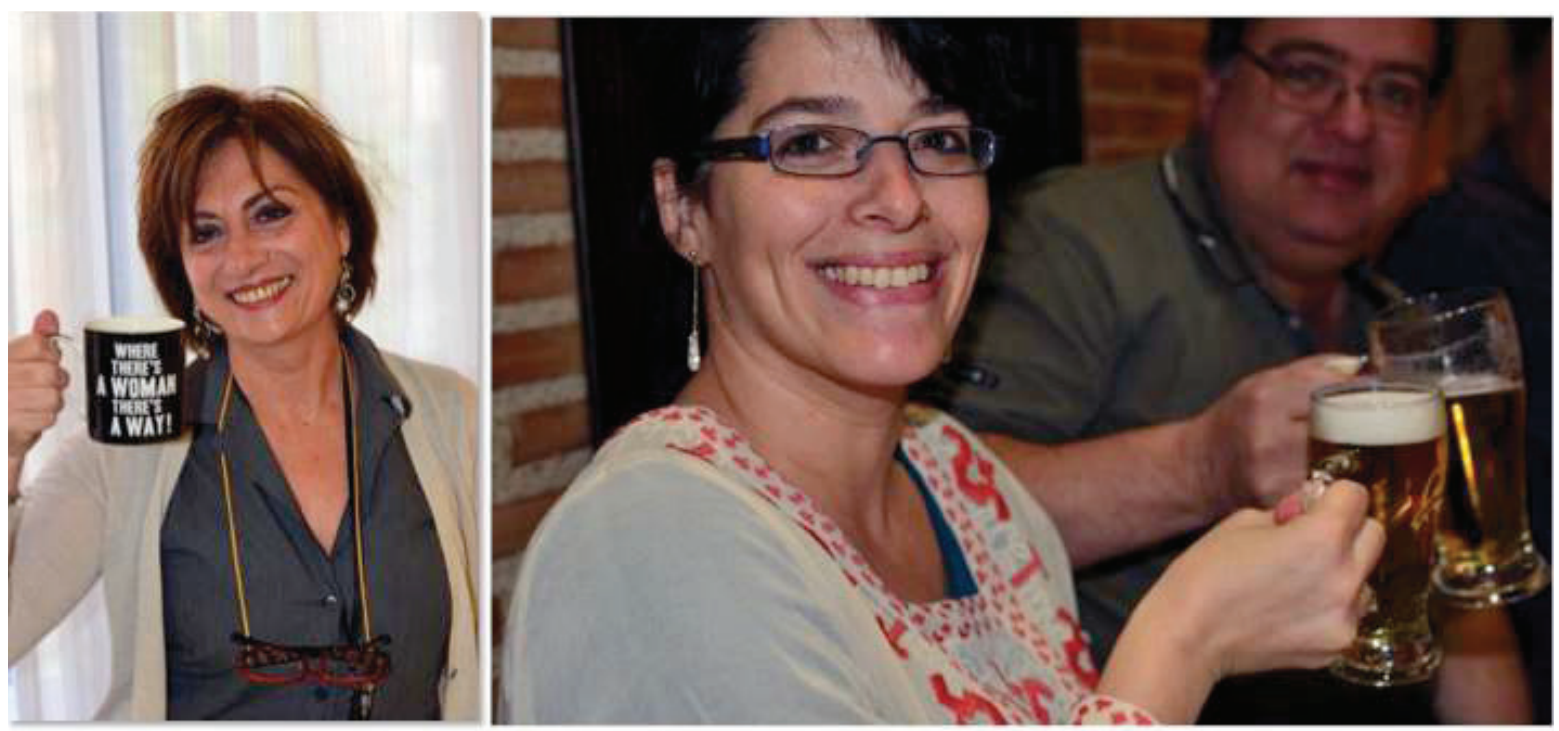

Figure 6. Left-hand pane, a reward for Domenica D'Elia for sterling work as P\&PR PC Chair; right-hand pane, a toast to Vicky Schneider, representative of new organisational member, TGAC.

but clearly, we need to do more. It was recognised that we need to improve our publicity and outreach activities, and that we could and should be doing a lot more both to attract student members and to give them visibility within EMBnet. Other ideas included merchandising (e.g., EMBnet T-shirts!), advertisements in the journal, and possibly attracting donations (which are within our statutes to receive). We should also be proactively consulting development agencies (UNESCO, etc.) and seeking joint research projects via national and international funding bodies.

\section{Video conferencing}

Maintaining the momentum of EMBnet's activities between AGMs is always a challenge, a challenge that rests with the PC Chairs and EB to address. At one time, it was possible to hold interim Committee meetings, Executive meetings and meetings of the full Board using a (commercial) online conferencing system called Marratech. However, the company was taken over, the software was suddenly no longer available, and we were obliged to find a new solution. After several trials, most monthly meetings of the $\mathrm{EB}$ and $\mathrm{OB}$ have been conducted with Skype, but this continues to cause problems for many participants. This has become an issue, especially for the bimonthly meetings of the full Board, because a great deal of time is wasted while people try (often unsuccessfully) to connect: this prohibits ef- ficiency, destroys morale, and increasingly deters people from attending.

In consequence, it was agreed that EMBnet will conduct an experiment to test around a dozen video-conferencing packages. Participants in the experiment would need to confirm their commitment after the AGM, a protocol for conducting the experiment would be agreed during the summer, and global testing would commence towards the beginning of the autumn. Ultimately, this should provide the optimal solution for all involved, and the results would be made available as a publication in EMBnet.journal.

\section{Future priorities}

In thinking about the future of EMBnet, it has been imperative to reflect on the impact of globalisation on our once-European organisation, and to better define EMBnet's role in the global bioinformatics landscape. As EMBnet has evolved, so too has its mission and its priorities. Accordingly, the question was what EMBnet's missions and priorities should now be, and what we should be doing to help get us there.

In terms of missions, there was general consensus that to promote, "Bioinformatics without borders" should be our primary goal. EMBnet should disseminate best practice in bioinformatics, promote bioinformatics capacity in all countries, share bioinformatics knowledge, and, crucially, incubate new initiatives (e.g., like GOBLET). 
EMBnet's priorities were considered to be to champion education and training; to achieve better PR and outreach; to improve the roll-out and recognition of EMBnet.journal; to make better use of our website in order to share more with our communities; to invest strategically in our activities; and, wherever possible, to apply jointly for funds to help realise our research, training and networking objectives.

\section{Conclusion}

It's clear that EMBnet has come a long way in the last three years, largely thanks to the enormous efforts of a handful of individuals. Thanks are especially due to Lubos Klucar for his work in running EMBnet.journal; to Erik Bongcam-Rudloff for coordinating the SeqAhead and AllBio projects, and to Andreas Gisel, who helps him to keep these projects on track; and finally, to Domenica D'Elia for her indefatigable work as EMBnet's most passionate and committed P\&PR PC Chair - see Figure 6.

During the 2013 meeting, we were also fortunate to be able to celebrate the arrival of our latest organisational member, The Genome Analysis Centre $^{17}$ (TGAC), represented by Vicky Schneider, who immediately stepped up to take on many new tasks (Figure 6).

The workshop and business meeting were lively affairs, packed to the brim with activities, and suggesting much work that's still to be done. We therefore call on everyone's ongoing support and collaboration to help us evolve EMBnet into a more innovative and ultimately more productive organisation. In particular, we hope that others will take the lead of those who've shouldered so much of EMBnet's work in recent years, and will join us in our efforts to make EMBnet the preeminent bioinformatics network in the world. And perhaps some of us may yet live to see EMBnet celebrate its golden anniversary!

\section{Acknowledgements}

We are indebted to Ana Alvarez and Ana Conesa for their considerable efforts with the local organisation, especially for their restaurant recommendations, and overall, for providing such a comfortable and welcoming environment.

\section{References}

Attwood TK, Bongcam-Rudloff E, Gisel A, de Villiers E (2010) EMBnet - the European Molecular Biology Network, Moving forward: 2010 \& beyond. EMBnet.journal 16(1): 8-14.

Attwood TK, Gisel A, Eriksson N-E, Bongcam-Rudloff E (2011) Concepts, historical milestones and the central place of bioinformatics in modern biology: a European perspective. In: Bioinformatics - Trends and Methodologies, Mahdavi MA Ed., Intech Online Publishers, November 2011, ISBN 978-953-307-282-1.

ISCB Press Release (2011) ISCB and EMBnet to collaborate on bioinformatics education and training. EMBnet.journal 17(1): 6.

Schneider MV, Walter P, Blatter MC, Watson J, Brazas MD, Rother K, Budd A, Via A, van Gelder CWG, Jacob J, Fernandes P, Nyronen T, De Las Rivas J, Blicher T, Loveland J, McDowall J, Jones P, Vaughan B, Lopez R, Attwood TK, Brooksbank C (2012) Bioinformatics Training Network (BTN): A community resource for bioinformatics trainers. Briefings in Bioinformatics 13(3): 383-389. doi: 10:1093/bib/bbr064 